九州大学学術情報リポジトリ

Kyushu University Institutional Repository

\title{
Photoreactions of Nitrodiphenyl Ethers
}

Ohnishi, Jun-ichi

Laboratory of Pesticide Chemistry, Faculty of Agriculture, Kyushu University

Eto, Morifusa

Laboratory of Pesticide Chemistry, Faculty of Agriculture, Kyushu University

https://doi.org/10.5109/24016

出版情報：九州大学大学院農学研究院紀要. 37 (3/4)，pp.247-255，1993-03. Kyushu University バージョン：

権利関係: 


\title{
Photoreactions of Nitrodiphenyl Ethers
}

\author{
Jun-ichi Ohnishi* and Morifusa Eto \\ Laboratory of Pesticide Chemistry, Faculty of Agriculture, \\ Kyushu University 46-02, Fukuoka 812, Japan
}

(Received September 21, 1992)

\begin{abstract}
Photoinduced nucleophilic substitution reactions of thirty $p$-nitrodiphenyl ethers including the herbicides nitrofen and chlornitrofen with a variety of amines were examined. The reaction took place by liberating nitrophenoxide or nitrite, depending on the substituents. Nitrofen liberated mainly nitrophenoxide by reactions with pyridine and 4methylpyridine to give N-phenylpyridinums, whereas chlornitrofen liberated exclusively nitrite to afford N-phenyoxyphenylpyridinums. In organic solvents photoreduction of the nitro group occurred to form nitroso and azo compounds.
\end{abstract}

\section{INTRODUCTION}

Many $p$-nitrodiphenyl ethers (nitro DPE; I) have been utilized as herbicides (Matsunaka, 1976). They show interesting structure-activity relationships in relation to light-dependency of their herbicidal activity. Matsunaka (1976) divided them into two groups. The major group includes nitrofen (NIP; 2,4-dichlorophenyl p-nitrophenyl ether), chlornitrofen (CNP; 2,4,6-trichlorophenyl p-nitrophenyl ether) and others, whose structure is characterized by at least one ortho-substitution on the benzene ring "A", and requires light for the activity. Another group active even in the dark has $m$ substituent(s) on the "A ring" as exemplified by TOPE ( $p$-nitrophenyl m-tolyl ether) and DMNP ( $p$-nitrophenyl 3,5-xylyl ether). We found that $0, m$-type DPEs which have substituents both at $\mathrm{o}$-and $\mathrm{m}$-positions exert herbicidal activity in the dark more than in the light (Ohnishi et al., 1992). Moreover $m, p$-type DPEs having substituents at $\mathbf{m}$ - and p-positions are inhibited their herbicidal activity by light.

On the other hand the fate of herbicide residues in the natural environment is greatly affected by sun-light (Crosby, 1976). Steller and Lestinger (1970) found two types of photoinduced aromatic substitution reactions of $p$-nitro DPEs in aqueous pyridine by displacing nitrite and $p$-nitrophenoxide. Such reaction appears to have certain role in the environmental dissipation of nitro-DPE herbicides (Nakagawa and Crosby, 1974b). Furthermore we have found that the amino analog of nitrofen has a high herbicidal activity (Ohnishi et al., 1993). The reduction of the nitro group in DPEs to the amino group occurs in flooded paddy soil and in plants (Kuwatsuka, 1977). This paper deals with the photoinduced reactions of DPEs. The photonucleophilic displacement reactions are greatly affected by the substituents and the photoreduction of nitrofen produces a nitroso and then azo compounds.

* Present address: Takarazuka Research Center, Sumitomo Chemical Co., Ltd., Takarazuka 665, Japan. 


\section{MATERIALS AND METHODS}

\section{Chemicals}

$p$-Nitro DPEs used in this study were synthesized and purified in this laboratory and their analytical data were listed in our previous paper (Ohnishi et al., 1993).

\section{A pparatus}

Photoreactions were carried out in a UVL-100P photochemical reactor equipped with a high pressure mercury lamp (Riko Chemical Ind., $\lambda>300 \mathrm{~nm}$ ) cooled by running water at room temperature. Ultraviolet (UV) spectra were recorded on a Shimazu UV-200 spectrophotometer.

\section{Photoinduced Nucleophilic Substitutions}

The reaction mixture consisted of a DPE $\left(10^{-4} \mathrm{M}\right)$ and a base $(1 \mathrm{M})$ in water for pyridine or 4-methylpyridine. Aqueous tert-butyl alcohol solutions (20\%) were used for the reaction with $1 \mathrm{M}$ ammonia, methylamine and dimethylamine. For reacations with thiophenol, cysteine, glycine, glycine ethyl ester, imidazole and histidine, aqueous tert-butyl alcohol or isopropanol was employed.

From the reaction mixture irradiated internally with UV under bubbling a nitrogen stream samples were periodically removed to analyze p-nitrophenoxide and/or nitrite ion liberated. $p$-Nitrophenoxide was determined by the optical density at 400 $\mathrm{nm}$ and nitrite was at $520 \mathrm{~nm}$ after diazocoupling of $\alpha$-naphthylamine with sulfanilic acid. The data are presented in the form of pseudo-first order rate constant $(k)$ of whole reaction and \% of each liberated product after almost completion of the reaction.

Liberated p-nitrophenoxide was identified by comparison with authentic sample on thin-layer chromatography (TLC). For the isolation and characterization of photoinduced nucleophilic reaction products, the reactions of nitrofen and chlornitrofen with pyridine and 4-methylpyridine were used as typical examples. The products were crystallized and analyzed after deriving to their picrates. The irradiated reaction mixture was concentrated by evaporation under reduced pressure. The residue in the case of reaction with pyridine was dissolved in a minimum amount of ethanol, treated with a saturated solution of picric acid in ethanol, and the precipitate was recrystallized from aqueous ethanol. In the case of 4-methylpyridine, the colored residue was dissolved in water and extracted with ether to remove the colored materials. The picrate was obtained from the aqueous solution by treating with an aqueous saturated sodium picrate and recrystallized from aqueous ethanol.

$N$-(2,4-Dichlorophenyl)pyridinum picrate, $\mathrm{mp} 184-5^{\circ} \mathrm{C}$, was obtained by irradiation of nitrofen in pyridine and water and treating the product with picric acid. Anal. Found: C, 44.83; H, 2.15; N, 12.33. Calcd. for $\mathrm{C}_{17} \mathrm{H}_{10} \mathrm{~N}_{4} \mathrm{O}_{7} \mathrm{Cl}_{2}$ : C, 44.95; H, 2.44; N, 12. $34 \%$.

$N-\left(2,4-\right.$ Dichlorophenyl)-4-methylpyridinum picrate, $\mathrm{mp} 196-7^{\circ} \mathrm{C}$, was similarly obtained from nitrofen and 4-methylpyridine. Anal. Found: C, 46.14; H, 2.54; N, 11. 84. Calcd. for $\mathrm{C}_{18} \mathrm{H}_{12} \mathrm{~N}_{4} \mathrm{O}_{7} \mathrm{Cl}_{2}: \mathrm{C}, 46.27 ; \mathrm{H}, 2.59 ; \mathrm{N}, 11.99 \%$.

$\mathrm{N}-\left[4-(2,4,6-\right.$ Trichlorophenoxy)phenyl $]$ pyridinum picrate, $\mathrm{mp} 150^{\circ} \mathrm{C}$, was obtained by irradiation of chlornitrofen in aqueous pyridine followed by treating with sodium 
picrate. Anal. Found: C, 47.64; H, 2.25; N, 9.50. Calcd. for $\mathrm{C}_{23} \mathrm{H}_{13} \mathrm{~N}_{4} \mathrm{O}_{8} \mathrm{Cl}_{3}: \mathrm{C}, 47.57$; $\mathrm{H}, 2.43 ; \mathrm{N}, 9.65 \%$.

$\mathrm{N}-\left[\right.$ 4-(2,4,6-Trichlorophenoxy)phenyl]-4-methylpyridinum picrate, mp $160-2^{\circ} \mathrm{C}$, was similarly obtained from chlornitrofen and 4-methylpyridine. Anal. Found: C, 48.44; $\mathrm{H}, 2.74 ; \mathrm{N}, 9.15$. Calcd. for $\mathrm{C}_{24} \mathrm{H}_{15} \mathrm{~N}_{4} \mathrm{O}_{8} \mathrm{Cl}_{3}: \mathrm{C}, 48.55 ; \mathrm{H}, 2.55 ; \mathrm{N}, 9.44 \%$.

\section{Photoreduction of Nitrofen}

Nitrofen $(0.01 \mathrm{M})$ in isopropanol in the presence or absence of potassium hydroxide $(0.01 \mathrm{M})$ was irradiated with a high pressure mercury lamp under nitrogen bubbling for $24 \mathrm{hr}$. Nitrofen was determined by absorption at $295 \mathrm{~nm}$. Acetone produced by oxidation of isopropanol was derived to 2,4-dinitrophenylhydrazone by treating the photoreaction mixture with the sulfuric acid solution of 2,4-dinitrophenylhydrazine and identified by TLC. After the photoreaction the reaction mixture was concentrated and water and ether were added to the residue. Chloride ion in the water layer was determined by Volhard's method. The ether layer was concentrated by evaporation and chromatographed on a silicic acid column eluted with a benzene-hexane (1:3) mixture. Obtained products were recrystallized from ethyl acetate or ethanol.

\section{RESULTS AND DISCUSSION}

\section{Photonucleophilic Substitution Reactions}

$p$-Nitro DPEs underwent two types of nucleophilic substitution on their photoinduced reactions in the presence of amines; i.e, (a) displacement of 4-nitrophenyl or (b) nitro group by an amine (Scheme 1). The release of p-nitrophenoxide was determined by measuring UV absorption at $400 \mathrm{~nm}$ and confirmed by comparison with the authentic $p$-nitrophenol on silica-gel TLC developed with three kinds of solvent systems: Rf values for ether-benzene (1:1), ether, and methanol were $0.45,0.80$, and 0 . 95, respectively. Nitrite ion was determined by diazo coupling method. The pyridinum products were isolated as picrates from the reaction mixtures of nitrofen (14) and chlornitrofen (16) in aqueous pyridines as typical examples, because the former liberated mainly phenoxide, whereas the latter did exclusively nitrite. The picrates of $\mathrm{N}$-(2,4-dichlorophenyl)-pyridinum and -4-methylpyridinum were isolated from nitrofen reaction mixtures with pyridine and 4-methylpyridine, respectively. On the other hand chlornitrofen gave the picrates of $\mathrm{N}$ - [4-(2,4,6-trichlorophenoxy)phenyl]pyridinum and $-4-$ methylpyridinum, respectively.

The reaction rates and the yields of liberated products at almost completion on the photoinduced nucleophilic substitutions of 30 different $p$-nitroDPEs with pyridine and 4-methyl pyridine are listed in Table 1. Introduction of a chlorine atom at the ortho position on the " $A$ " ring greatly accelerates the reaction rate, whereas that on meta or para affects little (compare 1, 2, 7 and 11). Additional chlorine atom rather retards the reaction in comparison with the o-monochloro DPE (compare 2, 4, 13, 16, 24, 26 and 29). Particularly m-chloro group reduces the reactivity (compare 24 and 26 with 13). If compare with $m$ - or $p$-chloro DPE, another chlorine atom does not much retard but rather increases the reaction rate (compare 7, 9, 11 and 19). The electrondonative methyl group generally retards the reaction. All the methyl- substituted DPEs are less active than any corresponding chlorine analogs with one exception of 2 , 6-dimethyl DPE (6) whch is more active than 2,6-dichloro (4) and 2-chloro-6-methyl 

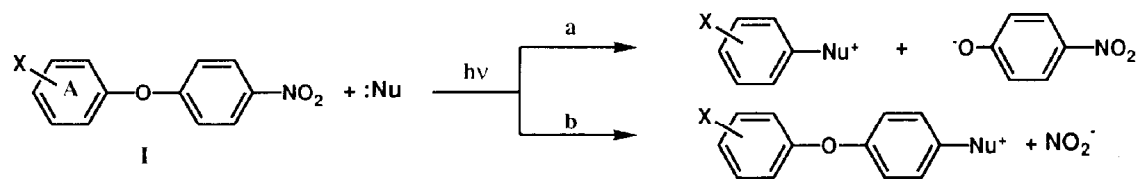

Scheme 1. Photoinduced nucleophilic displacement reactions.

Table 1. Rates and Products in Photoinduced Reactions of Nitrodiphenyl Ethers (I) with Pyridines.

\begin{tabular}{|c|c|c|c|c|c|c|c|c|c|}
\hline \multirow[b]{2}{*}{ No. } & \multirow[b]{2}{*}{$\begin{array}{l}\text { Substituent } \\
\mathrm{X}\end{array}$} & \multicolumn{4}{|c|}{ Pyridine } & \multicolumn{4}{|c|}{ 4-Methylpyridine } \\
\hline & & $\begin{array}{c}\mathrm{k} \\
\left(10^{-2} \mathrm{~min}^{-1}\right)\end{array}$ & $\begin{array}{l}\text { Time } \\
(\min )\end{array}$ & $\begin{array}{l}\text { Phenoxide } \\
(\%)\end{array}$ & \multicolumn{2}{|c|}{$\begin{array}{l}\text { Nitrite } \mathrm{k} \\
(\%)\left(10^{-2} \mathrm{~min}^{-1}\right)\end{array}$} & $\begin{array}{l}\text { Time } \\
\text { ( m i n ) }\end{array}$ & $\begin{array}{l}\text { Phenoxide } \\
(\%)\end{array}$ & $\begin{array}{c}\text { Nitrite } \\
(\%)\end{array}$ \\
\hline 1 & $\mathrm{H}$ & 6.1 & 40 & a4 & 7 & 7.3 & 40 & 94 & 3 \\
\hline $\mathrm{O}_{2}^{-}$ & $2-C 1$ & 100 & in & 80 & 10 & 308 & 15 & 80 & 7 \\
\hline 3 & $2-\mathrm{Me}$ & $\begin{array}{r}19.0 \\
1.8\end{array}$ & $\begin{array}{r}40 \\
120\end{array}$ & $\begin{array}{l}89 \\
95\end{array}$ & $\begin{array}{r}10 \\
5\end{array}$ & $\begin{array}{r}30.8 \\
6.0\end{array}$ & $\begin{array}{l}15 \\
50\end{array}$ & $\begin{array}{l}89 \\
92\end{array}$ & $\begin{array}{l}7 \\
3\end{array}$ \\
\hline 4 & $2,6-\mathrm{Cl}_{2}$ & 3.6 & 70 & 0 & 92 & & & & \\
\hline 5 & $2-\mathrm{Cl}-6-\mathrm{Me}$ & 4.6 & 60 & 36 & 64 & & & & \\
\hline 6 & $2,6-\mathrm{Me}_{2}$ & 6.4 & 50 & 96 & 0 & & & & \\
\hline \multicolumn{10}{|l|}{$m-$} \\
\hline 7 & $3-\mathrm{Cl}$ & 4.0 & 40 & 34 & 46 & 7.6 & 40 & 39 & 58 \\
\hline 8 & 3-Me & 1.4 & 250 & 85 & 12 & 8.1 & 120 & 82 & 7 \\
\hline 9 & $3,5-\mathrm{Cl}_{2}$ & 3.7 & 40 & 0 & 77 & 4.2 & 30 & 0 & 72 \\
\hline 10 & $3,5-\mathrm{Me}_{2}$ & 0.16 & 360 & 28 & 17 & 0.39 & 330 & 52 & 21 \\
\hline \multicolumn{10}{|l|}{$p-$} \\
\hline 11 & $4-\mathrm{Cl}$ & 5.0 & 60 & 82 & 18 & 7.3 & 40 & 94 & 3 \\
\hline 12 & 4-Me & 0.54 & 300 & 75 & 13 & 2.0 & 120 & 85 & 10 \\
\hline \multicolumn{10}{|l|}{$o, p^{-}$} \\
\hline 13 & $2,4-\mathrm{Cl}_{2}$ & 17.3 & 20 & 80 & 17 & 2.8 & 50 & 69 & 6 \\
\hline 14 & $2-\mathrm{Me}^{-4}-\mathrm{Cl}$ & 0.98 & 160 & 65 & 14 & 4.2 & 80 & 89 & 6 \\
\hline 15 & $2,4-\mathrm{Me}_{2}$ & 0.31 & 360 & 54 & 13 & 0.84 & 210 & 81 & 6 \\
\hline 16 & $2,4,6-\mathrm{Cl}_{3}$ & 13.0 & 20 & 0 & 93 & 4.3 & 30 & 0 & 73 \\
\hline 17 & $2,4-\mathrm{Cl}_{2}-6-\mathrm{Me}$ & 3.9 & 60 & 44 & 47 & 3.2 & 50 & 38 & 42 \\
\hline 18 & $2,4,6-\mathrm{Me}_{3}$ & 0.92 & 180 & 58 & 23 & & & & \\
\hline \multicolumn{10}{|c|}{$m, p^{-}$} \\
\hline 19 & $3,4-\mathrm{Cl}_{2}$ & 6.4 & 30 & 36 & 50 & 9.7 & 20 & 38 & 48 \\
\hline 20 & $3-\mathrm{Me}^{-4}-\mathrm{Cl}$ & 0.45 & 190 & 38 & 20 & 1.2 & 150 & 60 & 23 \\
\hline 21 & $3,4-\mathrm{Me}_{2}$ & 0.14 & 360 & 25 & 15 & 0.20 & 360 & 44 & 8 \\
\hline 22 & $3,4,5-\mathrm{Me}_{3}$ & 0.28 & 330 & 40 & 21 & 0.24 & 300 & 35 & 17 \\
\hline 23 & $3,5-\mathrm{Me}_{2}-4-\mathrm{Cl}$ & 1.20 & 40 & 32 & 8 & & & & \\
\hline \multicolumn{10}{|c|}{$o, m^{-}$} \\
\hline 24 & $2,3-\mathrm{Cl}_{2}$ & 1.4 & 210 & 46 & 58 & & & & \\
\hline 25 & $2,3-\mathrm{Me}_{2}$ & 0.32 & 300 & 50 & 22 & & & & \\
\hline 26 & $2,5-\mathrm{Cl}_{2}$ & 2.0 & 100 & 22 & 68 & & & & \\
\hline 27 & $2,5-\mathrm{Me}_{2}$ & 0.39 & 300 & 43 & 26 & & & & \\
\hline 28 & $2,3,5-\mathrm{Me}_{3}$ & 0.27 & 300 & 26 & 31 & & & & \\
\hline \multicolumn{10}{|c|}{$o, m, p-$} \\
\hline 29 & $2,4,5-\mathrm{Cl}_{3}$ & 3.7 & 100 & 55 & 45 & & & & \\
\hline 30 & $2,4,5-\mathrm{Me}_{3}$ & 0.31 & 340 & 36 & 29 & & & & \\
\hline
\end{tabular}


analogs (5).

Selectivity in photoinduced nucleophilic substitution site is greatly affected by the substituents on the "A" ring. Nitrophenoxide liberation (path a) on reaction with pyridines occurred predominantly in non-substituted and all the mono-chloro- or methyl-phenyl $p$-nitrophenyl ethers except 3-chloro analog (7) which appears nonselective. Introduction of another substituent(s) causes great change in the selectivity. Additional chlorine atome makes in some time reverse the selectivity to displace the nitro group (path b); 2,6-dichloro (4),3,5-dichloro (9),2,4,6-trichloro (16) are exclusively selective to path $\mathrm{b}$ in contrast to their corresponding less chloro analogs 2,7 and 13, respectively, which obey mainly to path a. The effect of additional methyl group is not distinctive. Steller and Lestinger (1970) have reported that such a strong electronwithdrawing group as nitro and cyano favors reaction by path $b$ (nitrite displacement) relative path a (nitrophenoxide displacement). Pyridine and 4-methylpyridine show similar tendency in reaction selectivity and reactivity, although the latter appears be at a little higher level in the selectivity and more active than the former except against 13 and 16.

Table 2 shows the results of reactions with methylamine, dimethylamine, and ammonia. The effects of the "A" ring substituent on the rate of reaction with methylamine and dimethylamine are less distinctive in comparison with pyridines. Methyl-substituted $p$-nitro-DPEs favor the phenoxide displacement by methylamine as seen in 3, 8, 10, 15, 21 and 22. Chloro analogs are less selective in general. Dimethylamine is much less active than methylamine. Reaction rate of ammonia was

Table 2. Rates and Products in Photoinduced Reactions of Nitrodiphenyl Ethers (I) with Amines and Ammonia.

\begin{tabular}{|c|c|c|c|c|c|c|c|c|c|c|c|c|c|}
\hline \multirow[b]{2}{*}{ No. } & \multirow[b]{2}{*}{$\begin{array}{l}\text { Substituent } \\
\mathrm{X}\end{array}$} & \multicolumn{4}{|c|}{ Methylamine } & \multicolumn{4}{|c|}{ Dimethylamine } & \multicolumn{4}{|c|}{ Ammonia } \\
\hline & & $\begin{array}{c}\mathrm{k} \\
\left(10^{-2} \mathrm{~min}^{-1}\right)\end{array}$ & $\begin{array}{l}\text { Time } \\
(\mathrm{min})\end{array}$ & $\begin{array}{r}\text { Phenoxide } \\
(\%)\end{array}$ & $\begin{array}{l}\text { Nitrite } \\
(\%)\end{array}$ & $\begin{array}{c}\mathrm{k} \\
\left\{10^{-2} \mathrm{~min}^{-1}\right\}\end{array}$ & $\begin{array}{l}\text { Time } \\
\text { (min) }\end{array}$ & $\begin{array}{r}\text { Phenoxide } \\
(\%)\end{array}$ & $\begin{array}{r}\text { Nitrite } \\
(\%)\end{array}$ & $\begin{array}{c}\mathrm{k} \\
\left(10^{-2} \min ^{-1}\right)\end{array}$ & $\begin{array}{l}\text { Time P } \\
(\min )\end{array}$ & $\begin{array}{r}\text { Phenoxide } \\
(\%)\end{array}$ & $\begin{array}{r}\text { Nitrite } \\
\text { (\%) }\end{array}$ \\
\hline 1 & $\mathrm{H}$ & 2.8 & 80 & 75 & 19 & 0.86 & 90 & 42 & 13 & & & & \\
\hline 2 & $2-\mathrm{Cl}$ & 4.9 & 50 & 65 & 26 & 1.1 & 90 & 54 & 8 & & & & \\
\hline 3 & $2-\mathrm{Me}$ & 5.0 & 60 & 75 & 9 & 0.82 & 90 & 44 & 8 & & & & \\
\hline 7 & $3-\mathrm{Cl}$ & 2.0 & 70 & 54 & 22 & 0.74 & 60 & 30 & 6 & 4.4 & 40 & 83 & 0 \\
\hline 8 & $3-\mathrm{Me}$ & 1.9 & 100 & 71 & 19 & 0.68 & 60 & 23 & 11 & 3.2 & 30 & 62 & 0 \\
\hline 9 & $3,5-\mathrm{Cl}_{2}$ & 2.6 & 90 & 42 & 49 & 0.48 & 60 & 19 & 6 & 4.1 & 30 & 29 & 42 \\
\hline 10 & 3,5-Me, & 3.9 & 80 & 91 & 7 & 0.27 & 120 & 17 & 11 & 2.6 & 30 & 54 & 0 \\
\hline 11 & $4-\mathrm{Cl}$ & 6.1 & 50 & 78 & 17 & 1.2 & 90 & 60 & 5 & 4.4 & 40 & 83 & 0 \\
\hline 12 & $4-\mathrm{Me}$ & 2.3 & 90 & 76 & 12 & 0.37 & 120 & 18 & 18 & & & & \\
\hline 13 & $2,4-\mathrm{Cl}_{2}$ & 8.1 & 50 & 79 & 28 & 1.4 & 100 & 61 & 11 & 18.4 & 25 & 99 & 0 \\
\hline 14 & $2-\mathrm{Me}^{-4}-\mathrm{Cl}$ & 5.3 & 40 & 68 & 24 & 0.86 & 140 & 57 & 14 & 7.6 & 60 & 99 & 0 \\
\hline 15 & $2,4-\mathrm{Me}_{2}$ & 2.4 & 100 & 86 & 9 & 0.27 & 140 & 20 & 12 & & & & \\
\hline 16 & $2,4,6-\mathrm{Cl}_{3}$ & 3.2 & 110 & 56 & 44 & 1.1 & 120 & 52 & 9 & 2.8 & 90 & 32 & 63 \\
\hline 17 & $2,4-\mathrm{Cl}_{2}-6-\mathrm{Me}$ & 2.6 & 90 & 51 & 43 & 0.65 & 120 & 41 & 14 & 10.5 & 30 & 47 & 49 \\
\hline 19 & $3,4-\mathrm{Cl}_{2}$ & 9.1 & 60 & 54 & 47 & 0.62 & 120 & 43 & 10 & & & & \\
\hline 20 & $3-\mathrm{Me}-4-\mathrm{Cl}$ & 4.8 & 50 & 62 & 28 & 0.45 & 160 & 33 & 19 & 1.4 & 70 & 63 & 0 \\
\hline 21 & $3,4-\mathrm{Me}_{2}$ & 2.0 & 100 & 78 & 9 & 0.34 & 120 & 14 & 19 & 0.44 & 90 & 33 & 0 \\
\hline 22 & $3,4,5-\mathrm{Me}_{3}$ & 7.4 & 40 & 87 & 9 & 0.33 & 120 & 14 & 18 & 0.56 & 120 & 24 & 25 \\
\hline 23 & $3,5-\mathrm{Me}_{2}-4-\mathrm{Cl}$ & 1.3 & 80 & 53 & 13 & 0.92 & 120 & 62 & 5 & 0.77 & 110 & 41 & 16 \\
\hline
\end{tabular}


much influenced by the ring substituent. Ammonia prefers to displace $p$-nitrophenoxide. Thus, many DPEs did not liberate nitrite on the photoinduced substitution reaction with ammonia. Even 3,5-dichloro (9) and 2,4,6-trichloro (16) derivatives, which exclusively liberated nitrite by pyridines (see Table 1), liberated considerable amounts of phenoxide on reaction with ammonia. This is probably due to less steric hindrance for the small moleclule of ammonia.

Observations on the rapid photoinduced reactions of $p$-nitro-DPEs with amines compeled us to examine their reactions with some biologically important nucleophiles. Reactions with some amino acids and related functionals with nitrofen and chlornitrofen were conducted. Imidazole reacted very slowly with nitrofen in aqueous $t$ butyl alcohol under UV-irradiation to liberate limitted amounts of both p-nitrophenoxide and nitrite, but not with chlornitrofen while the examined reaction time (10 hr). UV-Irradiation, however, did not cause histidine to react with nitrofen in aqueous isopropanol. Photoinduced substitution reactions of nitrofen and chlornitrnfen with thiophenol in aqueous t-butyl alcohol were not observed even in the presence of certain photosensitizers, but only diphenyl disulfide $\left(\mathrm{mp} 60-62^{\circ} \mathrm{C}\right)$ was isolated as a product from the reaction mixture. Cysteine reacted slowly with the p-nitro DPEs to liberate a small amount of $p$-nitrophenoxide. However, no substitution product but only cystine was isolated from the reaction mixture. Nitrofen reacted with glycine, but not with its ethyl ester, to liberate slowly both the phenoxide and nitrite. These observations suggest neither amino nor thiol groups in biological substances may not extensively undergo photoinduced substitution reactions with $p$-nitro-DPEs.

\section{Photoreduction of Nitrofen}

Irradiated with UV in isopropanol under nitrogen gas bubbling for $24 \mathrm{hr}$, nitrofen reacted $39 \%$ based on UV absorption at $295 \mathrm{~nm}$ and liberated $6.4 \%$ of chlorine. Acetone produced from isopropanol by photoreaction was derived to the 2,4-dinitrophenylhydrazone and identified by comparison with the authentic sample on silica gel TLC [Rf(solvent): 0.50 (chloroform); 0.39 (benzene)] . The photoreaction mixture gave at least six spots (from lowest Rf A to F) besides unreacted nitrofen on TCL. Fractions eluted by benzene-hexane mixture (1:3) before nitrofen from a silicic acid column chromatograph gave orange color crystals of product $\mathrm{E}, \mathrm{mp} 162-3^{\circ} \mathrm{C}$, in $5.4 \%$ yield. The mass spectrum of $\mathrm{E}$ indicated that the molecular mass $(\mathrm{M}+)$ is $\mathrm{m} / \mathrm{z} 502$ and four chlorine atoms are involved in the molecule (isotope abundance $\mathrm{M}+2,130 \%$; $\mathrm{M}+$ 4, 65\%). From these data including fragmentation ions $\left(\mathrm{m} / \mathrm{z} 265 \mathrm{Cl}_{2} \mathrm{PhOPhN}_{2}{ }^{+}, 237\right.$ (base) $\mathrm{Cl}_{2} \mathrm{PhOPh}^{+}$) and elemental analysis (Found: $\mathrm{C}, 56.89 ; \mathrm{H}, 2.90 ; \mathrm{N}, 5.34$. Calcd. for $\mathrm{C}_{24} \mathrm{H}_{14} \mathrm{~N}_{2} \mathrm{O}_{2} \mathrm{Cl}_{4}$ : C, 57.15; H, 2.80; N, 5.56\%), 4,4'-bis(2,4-dichlorophenoxy)azobenzene was proposed as the structure of $\mathrm{E}$.

In the presence of alkali nitrofen reacted $30 \%$, liberating $38 \%$ of chlorine. From the reaction mixture a product $\mathrm{F}\left(\mathrm{mp} 174-176^{\circ} \mathrm{C}\right)$ was obtained in $14 \%$ yield after silicic acid column chromatography. The mass spectrum showed that the product $\mathrm{F}$ has the molecular mass of 518 containing four chlorine atoms in the molecule (isotope abundance $\mathrm{M}+2,133 \% ; \mathrm{M}+4,64 \%$ ). Thus $\mathrm{F}$ may have one more oxygen atom additional to compound E. A fragment ion $\mathrm{m} / \mathrm{z} 281$ corresponds to the fragment ion $\mathrm{m} / \mathrm{z} 265$ of the product $\mathrm{E}$, indicating the additional oxygen atom is present in a moiety containing an azo group. From the mass spectrum data and elemental analysis product $\mathrm{F}$ was 
proposed as 4,4'-bis(2,4-dichlorophenoxy)azoxybenzene. Anal. Found: C, 56.05; H, 2. 75; N, 5.30. Calcd. for $\mathrm{C}_{24} \mathrm{H}_{14} \mathrm{~N}_{2} \mathrm{O}_{3} \mathrm{Cl}_{4}: \mathrm{C}, 55.41 ; \mathrm{H}, 2.75 ; \mathrm{N}, 5.44 \%$.

In order to decide the cis-trans geometry of the compounds $\mathrm{E}$ and $\mathrm{F}$, their $\mathrm{UV}$ spectra were compared with cis and trans isomers of azobenzene in Fig. 1. Both azo and azoxy compounds have generally two absorption maxima. trans-Isomers show stronger absorption maximum in longer wavelength region than that in shorter wavelength region, and the cis-isomers are inverse as exemplified by azobenzene. It is also the case in azoxybenzene (Nippon Kagakukai, 1965). Since compounds E and $\mathrm{F}$ have stronger absorption maximum in longer wavelength region, they are decided as trans isomers.

Green crystals $\left(\mathrm{mp} 67-69^{\circ} \mathrm{C}\right.$ ) were obtained after elution of $\mathrm{E}$ and $\mathrm{F}$ from the silicic acid column in about $22 \%$ yield. They were submitted to a column partition chromatography on $95 \%$ methanol coated celite and eluted with hexane saturated with 95\% methanol. Obtained fraction gave two major spots $\mathrm{C}$ and $\mathrm{D}$ on TLC ( $\mathrm{Rf}=0.50$ and 0.59) developed with hexane-acetone (4:1). They were isolated from TLC. Product $\mathrm{D}$ was colored by $\mathrm{PdCl}_{2}$ agent and purified by recrystallization from ethanol to give yellow crystals, $\mathrm{mp} 128^{\circ} \mathrm{C}$. MS m/z: $267\left(\mathrm{M}^{+}\right), 237(\mathrm{M}+-\mathrm{NO}), 202\left(\mathrm{M}^{+}-\mathrm{NO}-\mathrm{Cl}\right)$. The isotope abundance $(\mathrm{M}+2,66 \% ; \mathrm{M}+4,11 \%)$ indicates the presence of two chlorine atoms in the molecule. These data suggest product $\mathrm{D}$ is the nitroso derivative of nitrofen, that is, 2,4-dichlorophenyl $p$-nitrosophenyl ether. Product $\mathrm{C}$ was recrystallized from hexane, $\mathrm{mp} 126^{\circ} \mathrm{C}$. Anal. Found: C, 55.97; H, 2.74, N, 5.39\%. MS m/z: 297



Fig. 1. UV spectra of photoproducts $\mathrm{E}$ and $\mathrm{F}$ and cis and trans azobenzenes. - - cis-azobenzene; - - - trans-azobenzene. 
$\left(\mathrm{M}^{+}\right)$. The isotope abundance indicated it has no chlorine atom in the molecule. This must be a reductively dechlorinated product but could not be identified. The more polar photoproducts corresponding spots $\mathrm{A}$ and $\mathrm{B}$ may be more reduced compounds probably including amino derivatives and polimerized products but were not isolated for characterization.

Nakagawa and Crosby (1974b) and then Ruzo et a. (980) have found that photolysis of nitrofen in aqueous suspension occurred by rapid cleavage of the ether linkage and reduction of the nitro group, yielding $p$-nitrophenol, 2,4-dichlorophenol, and 2,4-dichloro-4'-amino-DPE as major products. 4,4'-Bis(2,4-dichlorophenoxy)azobenzene was also found (Nakagawa and Crosby, 1974b). Some azobenzene and azoxybenzene derivatives have been identified as photolysis products of trifluralin $(N$, $N$-dipropyl-2,6-dinitro-4-trifluoromethylaniline) in benzene solutions (Sullivan et al., 1980). The formation of a nitroso compound has also been observed in the photolysis of 2,4,6-trichloro-3'-methoxycarbonyl-4'-nitro DPE (Ruzo et d., 1980). Aromatic nitro compounds are reduced to amines via nitroso and hydroxylamine intermediates. The nitroso compounds condense with the hydroxylamines and amines to form azoxy and azo compounds, respectively (Scheme 2). Since the condensation reactions occur under alkaline conditions but are usually inhibited under acidic conditions (Coombes, 1979), the formation of azoxy or azo compounds from $p$-nitro DPE herbicides appears rather hard to occur in natural environment. Although some azo and azoxy compounds such as 4-dimethylaminoazobenzene are known to be carcinogenic, the activity depends upon the pattern of ring substitution (Sullivan \&d., 1980). On the other hand, the nitroso derivative has been suggested as an activation product of nitrofen (Draper and Casida, 1985). It may link to a membrane-unsaturated fatty acid and produce phytotoxic nitroxide free radical on autooxidation.

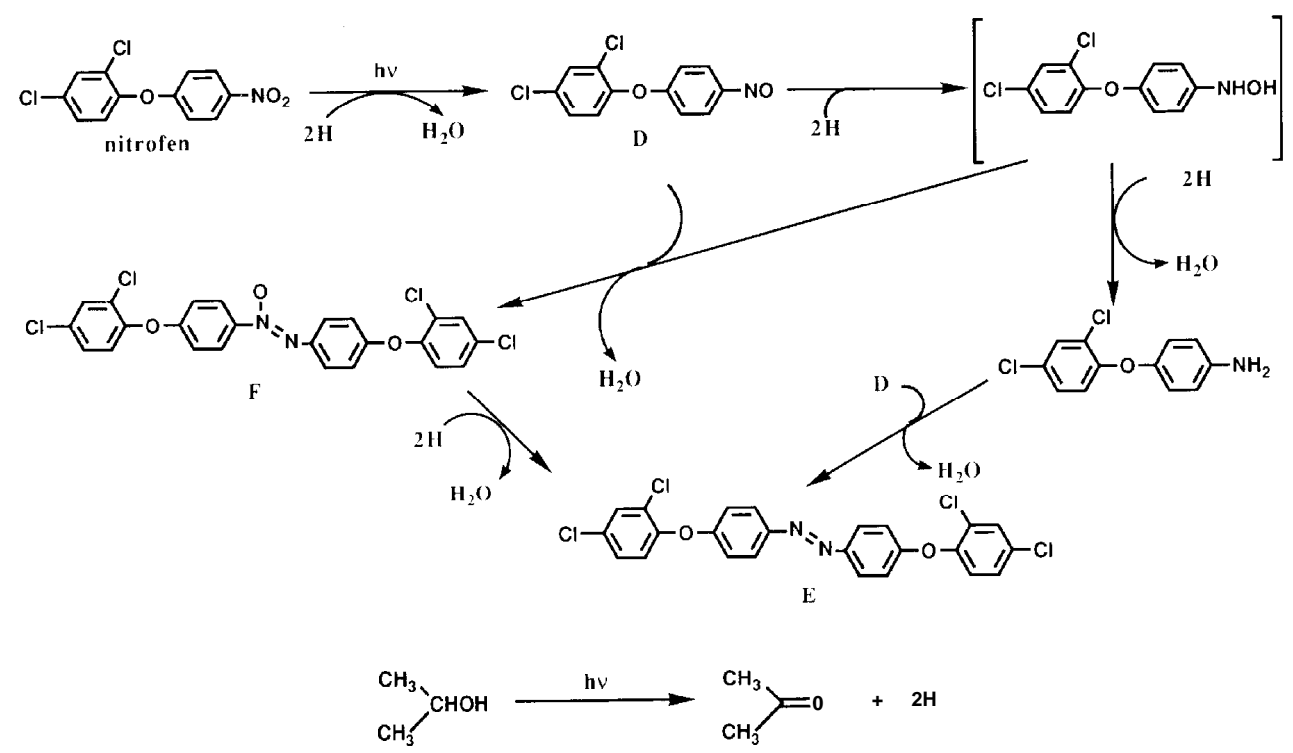

Scheme 2. Photoinduced reduction of nitrofen in isopropanol. 
Photoreduction is greatly accelerated in the presence of organic solvents, which serve as hydrogen sources. Similar conditions may occur on plant surface. Isopropanol is particularly effective as a hydrogen donor, transforming itself into acetone (Matsui et a., 1973). This is also the case for the reductive dehalogenation of haloaromatics.

In conclusion p-nitro DPEs readily react with some nucleophils under irradiation of UV light by displacing the nitrophenyl or nitro group. In the presence of appropriate hydrogen donors photoreduction of the nitro group and reductive dechlorination occur. Similar reactions may take place in some biological systems. They may contribute to some biological actions and also to the degradation of p-nitro DPEs in the natural environment. Organic substances in plant and soil may serve as not only nucleophils but also hydrogen donors for photoinduced reactions of nitro DPE herbicides.

\section{REFERENCES}

Coombes, R. G. 1979 Nitro and nitroso compounds. In "Comprehensive Organic Chemistry" Vol. 2, ed. by 1.0. Sutherland, Pergamon Press, Oxford, pp. 305-381

Crosby, D. G. 1976 Herbicide photodecomposition. In "Herbicides Chemistry, Degradation, and Mode of Acation", Vol. 2, ed. by P. C. Kearney and D. D. Kaufman, Marcel Dekker, New York, pp. $835-890$

Draper, W. M. and J. E. Casida 1985 Nitroxide radical adducts of nitrodiphenylether herbicides and other nitroaryl pesticides with unsaturated cellular lipids. J.Agric. Food Chem., 33: 103-108

Kuwatsuka, S. 1977 Studies on the fate and behavior of herbicides in soil and plant. J.Pestic. Sci., 2: 201-213

Matsui, Y., M. Eto and K. Maekawa 1973 Photochemical degradation of polychlorinated hydrocarbons. Bull. Agr. Chem. Soc. Japan, 10: 599-604

Matsunaka, S. 1976 Diphenyl ethers. In "Herbicides Chemistry, Degradation, and Mode of Action”, Vol. 2, ed. by P. C. Kearney and D. D. Kaufman, Marcel Dekker, New York, pp. 709-739

Nippon Kagakukai ed., "Jikkenn Kagaku Koza" Zoku 11, Maruzen, Tokyo, p. 329

Nakagawa, M. and D. G. Crosby 1974a Photodecomposition of nitrofen. J. Agr. Food Chem., 22: $849-853$

Nakagawa, M. and D. G. Crosby 1974b Photonucleophilic reactions of nitrofen. J. Agr. Food Chem., 22: 930-932

Ohnishi, J., K. Yukitake and M. Eto 1993 Structure-activity relationships of herbicidal p-nitrodiphenyl ethers. J.Fac. Agr., Kyushu Univ, 37: 239-246

Steller, K. E. and R. L. Lestinger 1970 Effects of distant substituents on photoinduced aromatic substitution reactions. J. Org. Chem., 35: 308-313

Sullivan, R. G., H. W. Knoche and J. C. Markle 1980 Photolysis of trifluralin: Characterization of azobenzene and azoxybenzene photodegradation products. J.Agr. Food Cheun., 28: 746-755 